\title{
Rapid generation of chromosome-specific alphoid DNA probes using the polymerase chain reaction
}

\author{
Ian Dunham $^{1 *}$, Christoph Lengauer ${ }^{2}$, Thomas Cremer ${ }^{2}$, and Terry Featherstone ${ }^{1}$ \\ ${ }^{1}$ Department of Genetics, Howard Hughes Medical Institute, Washington University School of Medicine, St. Louis, MO 63110, USA \\ ${ }^{2}$ Institut für Humangenetik und Anthropologie der Universität, Im Neuenheimer Feld 328, W-6900 Heidelberg, \\ Federal Republic of Germany
}

Received April 16, 1991/ Revised August 29, 1991

\begin{abstract}
Summary. Non-isotopic in situ hybridization of chromosome-specific alphoid DNA probes has become a potent tool in the study of numerical aberrations of specific human chromosomes at all stages of the cell cycle. In this paper, we describe approaches for the rapid generation of such probes using the polymerase chain reaction (PCR), and demonstrate their chromosome specificity by fluorescence in situ hybridization to normal human metaphase spreads and interphase nuclei. Oligonucleotide primers for conserved regions of the alpha satellite monomer were used to generate chromosome-specific DNA probes from somatic hybrid cells containing various human chromosomes, and from DNA libraries from sorted human chromosomes. Oligonucleotide primers for chromosome-specific regions of the alpha satellite monomer were used to generate specific DNA probes for the pericentromeric heterochromatin of human chromosomes 1 , $6,7,17$ and $X$ directly from human genomic DNA.
\end{abstract}

\section{Introduction}

Alpha satellite DNA is a primate-specific family of tandemly repeated sequences present in the centromeric regions of all human chromosomes (Manuelidis 1978; Rosenberg et al. 1978; Willard 1985). The basic unit is a monomer repeat of approximately $170 \mathrm{bp}$. In addition to regions that are strongly conserved among the different chromosomes, this monomer also contains variable regions. Blocks of consecutive monomers comprise a higherorder repeat of up to several kilobases in size. Specific multimeric higher-order repeat units have been described for most human chromosomes (for review see Willard and Waye 1987a).

In situ hybridization of alphoid probes cloned from conserved regions of the alphoid monomer has been applied to pinpoint centromeric regions (Mitchell et al.

* Present address: Paediatric Research Unit, The Prince Philip Research Laboratories, Guy's Tower, London Bridge SE1 9RT, UK

Offprint requests to: $\mathrm{T}$. Cremer
1985). In clinical cytogenetics, chromosome-specific alphoid probes have become an important aid for the detection of specific numerical chromosome aberrations and for the definition of marker chromosomes (Cremer et al. 1986, 1988b; Hopman et al. 1989; Anastasi et al. 1990; Poddighe et al. 1991). Recently, Koch et al. (1989) have used the polymerase chain reaction (PCR) for the rapid generation of alphoid DNA probes directly from somatic hybrid cells containing the human chromosomes $\mathrm{X}$ and 11. In their experiments, oligonucleotide primers were applied that anneal to conserved regions of the alphoid monomer.

In this study, we extend these observations and describe new possibilities for the rapid generation of alphoid DNA probes by PCR. First, in addition to the use of somatic hybrid cell lines, we demonstrate that primers for conserved regions are useful for the generation of chromosome-specific probes from DNA libraries constructed from sorted human chromosomes. Secondly, we demonstrate that oligonucleotide primers directed to the chromosome-specific variable regions of alphoid monomers can be used to generate chromosome-specific alphoid probes for in situ hybridization directly from human genomic DNA.

\section{Materials and methods}

\section{Cell lines}

The human-hamster hybrid cell line $\mathrm{Cl} 21$ was established in Dr. P. Goodfellow's laboratory (Imperial Cancer Research Fund Laboratories, London, UK) and kindly provided by Dr. P. Vogt (University of Heidelberg, FRG). This cell line contains an apparently normal human $\mathrm{X}$ chromosome as the only known human chromosome material, in practically all cells. The human-mouse cell line Rurag 6 was kindly provided by Dr. K. M. Grzeschik (University of Marburg, FRG) and contains human chromosomes 11 and 20 , the long arm of human chromosome 7 , and the long arm of the human X chromosome (Lengauer et al. 1990).

\section{Chromosome preparations}

Metaphase chromosome spreads were obtained from the above hybrid cell lines and from phytohemagglutinin(PHA)-stimulated 
normal male and female human lymphocytes using standard procedures (Cremer et al. 1988a). Preparations were stored in $70 \%$ ethanol at $4^{\circ} \mathrm{C}$ until use.

\section{DNA preparations}

Genomic DNA was prepared from male human blood and from the hybrid cell lines according to Maniatis et al. (1982). The plasmid DNA libraries from sorted human chromosomes 1,2 and 8 were the generous gift of Dr. J. W. Gray (Livermore, USA). Libraries were constructed from HindIII-digested DNA cloned in the Bluescribe vector (Stratagene).

Total genomic DNA from a yeast artificial chromosome (YAC)clone (yHPRT) with a 680 -kb long human sequence containing the HPRT-gene (Imai and Olson 1990; Huxley et al. 1991) was prepared as described by Green and Olson (1990).

\section{Oligonucleotide primers}

The first two primers were directed to a conserved region of the 171-bp monomer of human alpha satellite DNA (Willard and Waye 1987b) and were: $\alpha 27: 5^{\prime}$ CAT CAC AAA GAA GTT TCT GAG AAT GCT TC $3^{\prime}$ and $\alpha 30: 5^{\prime}$ TGC ATT CAA CTC ACA GAG TTG AAC CTT CC $3^{\prime}$. The second group of primers were directed to chromosome-specific regions of alphoid monomers and were: (1) chromosome-1-specific primers (Willard and Waye 1987b), a1E6: 5' GGC CTA TGG CAG CAG AGG ATA TAA CTG CC $3^{\prime}$ and $\alpha 1 \mathrm{~A} 7: 5^{\prime}$ GTG AGT TTT CTC CCG TAT CCA ACG AAA TCC $3^{\prime}$ (the length of the amplification product was $201 \mathrm{bp}$ ); (2) chromosome-6-specific primers (Jabs and Persico 1987), $\alpha 6 \mathrm{E}: 5^{\prime}$ ACT GTG GGC TTC AAT GCC GC $3^{\prime}$ and $\alpha 6 \mathrm{~F}$ : 5' GCC TAC GGC AGA AAA AGA AAC C $3^{\prime}$ (the length of the amplification product was $182 \mathrm{bp}$ ); (3) chromosome-7-specific primers (Waye et al. 1987), $\alpha 7$ A10: 5' TTC ATT GGA ATC GCG AAT AC 3 ' and $\alpha 7$ A $12: 5^{\prime}$ CAA GAA GGC TTC AAA GCA CC $3^{\prime}$ (the length of the amplification product was $348 \mathrm{bp}$ ); (4) chromosome-17-specific primers (Waye and Willard 1986; Willard and Waye 1987b), $\alpha 17$ A1: 5' AAT TCG TTG GAA ACG GGA TAA TTT CAG CTG $3^{\prime}$ and $\alpha 17 \mathrm{~B} 2: 5^{\prime}$ CTT CTG AGG ATG CTT CTG TCT AGA TGG C $3^{\prime}$ (the length of the amplification product was $227 \mathrm{bp}$ ); and (5) chromosome-X-specific primers (Waye and Willard 1985), $\alpha$ XC11: $5^{\prime}$ ATT TCT TTG GAA TCG GGA ATA TTT CCA CAG $3^{\prime}$ and $\alpha$ XD12: $5^{\prime}$ CTC TCG TCT TTC TGT GAA GAT AAA G $3^{\prime}$ (the length of the amplification product was $212 \mathrm{bp}$ ).

\section{PCR-conditions and probe labeling}

$P C R$ with primers $\alpha 27$ and $\alpha 30$. Samples (100 ng) of male human genomic DNA, hybrid cell line DNA or chromosome-specific DNA libraries were used in 5- $\mu$ l assays containing $5 \mu M$ of each of the two primers, $10 \mathrm{~m} M$ TRIS- $\mathrm{HCl}$ (pH 8.3), $50 \mathrm{~m} M \mathrm{KCl}, 1.5 \mathrm{~m} M$ $\mathrm{MgCl}_{2}, 0.001 \%$ gelatin, $200 \mu M$ of each of the four dNTPs, and 2.5 units of Thermus aquaticus DNA polymerase (Perkin Elmer/Cetus). After an initial denaturation at $92^{\circ} \mathrm{C}$ for $3 \mathrm{~min}, 30$ cycles were carried out with denaturation at $92^{\circ} \mathrm{C}$ for $50 \mathrm{~s}$, annealing at $64^{\circ} \mathrm{C}$ for $2 \mathrm{~min}$ and extension at $72^{\circ} \mathrm{C}$ for $3 \mathrm{~min}$. Amplified DNA products were biotinylated with biotin-11-dUTP by nick translation (Langer et al. 1981).

PCR with chromosome-specific alphoid primers. Samples (500 ng) of male human genomic DNA were used in $25 \mu 1$ assays containing $1 \mu M$ each of appropriate primer pair, $10 \mathrm{~m} M$ TRIS- $\mathrm{HCl}$ ( $\mathrm{pH} 8.3$ ), $50 \mathrm{~m} M \mathrm{KCl}, 2.5 \mathrm{~m} M \mathrm{MgCl}_{2}, 170 \mu \mathrm{g} / \mathrm{ml}$ bovine serum albumin, $200 \mu M$ each dATP, dCTP, dGTP, $100 \mu M$ each dTTP, bio-11dUTP, and 1.25 units of Thermus aquaticus DNA polymerase overlaid with $25 \mu \mathrm{l}$ mineral oil. A total of 25 cycles was carried out with denaturation at $92^{\circ} \mathrm{C}$ for $1 \mathrm{~min}$, annealing at $65^{\circ} \mathrm{C}$ for $2 \mathrm{~min}$, and extension at $72^{\circ} \mathrm{C}$ for $2 \mathrm{~min}$.

\section{In situ hybridization and probe detection}

In situ hybridization and washing procedures were performed essentially as described previously (Cremer et al. 1988b) with the following modifications. Between 5 to $20 \mathrm{ng}$ biotinylated alphoid PCR-amplified DNA was applied per slide using $24 \times 50 \mathrm{~mm}$ cover glasses. If necessary, a higher stringency was achieved by increasing the formamide concentration in the hybridization mixture from $50 \%$ to $70 \%$, and by an additional washing step with $0.1 \times \mathrm{SSC}$ $(1 \times \mathrm{SSC}=150 \mathrm{~m} M \mathrm{NaCl} / 15 \mathrm{~m} M$ sodium citrate, $\mathrm{pH} 7.0)$ at $60^{\circ} \mathrm{C}$ for $7 \mathrm{~min}$. For dual in situ hybridizations with the YAC-clone yHPRT (see above) and alphoid DNA specifically amplified from the X-chromosome, $100 \mathrm{ng}$ of biotin-labeled DNA from the YACcontaining strain was used with approximately $20 \mathrm{ng}$ biotinylated alphoid DNA, $50 \mu \mathrm{g}$ unlabeled total human DNA, $5 \mu \mathrm{g}$ salmon sperm DNA, and $50 \mu \mathrm{g}$ total yeast DNA.

Probe detection with avidin conjugated with fluorescein-isothiocyanate (FITC) was carried out as described previously (Cremer et al. 1988b). Signals were amplified once according to the protocol of Pinkel et al. (1986). Chromosome preparations were counterstained with $1 \mu \mathrm{g} / \mathrm{ml}$ 4,6 diamidino-2-phenylindole (DAPI) and $0.2 \mu \mathrm{g} / \mathrm{ml}$ propidium iodide mounted in fluroescence antifading buffer ( $1 \mathrm{mg}$ p-phenylendiamine in $1 \mathrm{ml}$ glycerine buffer, $\mathrm{pH}$ 8.0). Microphotographs were taken with a Zeiss photomicroscope III equipped for epifluorescence or a Zeiss Axiophot. Agfachrom 1000 RS color slide films were used. Chromosomes were identified by routine GTG-banding either before or after in situ hybridization (Klever et al. 1991; Gnirke et al. 1991) or by DAPI-banding applied after in situ hybridization (Cremer et al. 1988a).

\section{Results}

Fluorescence in situ hybridization with alphoid probes generated by PCR with oligonucleotide primers from alphoid consensus regions

Male human genomic DNA and genomic DNA from the hybrid cell lines RuRag 6 and $\mathrm{Cl} 21$ were amplified using the primer pair $\alpha 27 / \alpha 30$. Figure 1 shows examples of in situ hybridization experiments with biotinylated amplification products to normal male and female human metaphase spreads and interphase nuclei. Amplification products of male human genomic DNA produced signals on all centromeric regions in normal chromosome complements (Fig. 1a-c). In contrast, probes obtained by amplification of hybrid cell DNA stained the centromeric regions of specific human chromosomes, i.e., the chromosomes that were contained in the respective hybrid cell lines. As expected, PCR of the Cl21-hybrid DNA yielded a probe that labeled only the $\mathrm{X}$-centromeric heterochromatin (Fig. 1d). Accordingly, only one centromeric region was stained in normal male lymphocyte nuclei (data not shown), whereas in female nuclei, two signals could be detected (Fig. 1d). PCR products from the RuRag 6 hybrid cell line labeled the centromeric heterochromatin of human chromosomes 7, 11 and 20 (Fig. 1e, f). The X-centromeric heterochromatin was not stained by this probe, although the presence of human $\mathrm{X}$-chromosome material had previously been confirmed in RuRag 6 cells using chromosomal in situ suppression hybridization with a bacteriophage DNA library from 


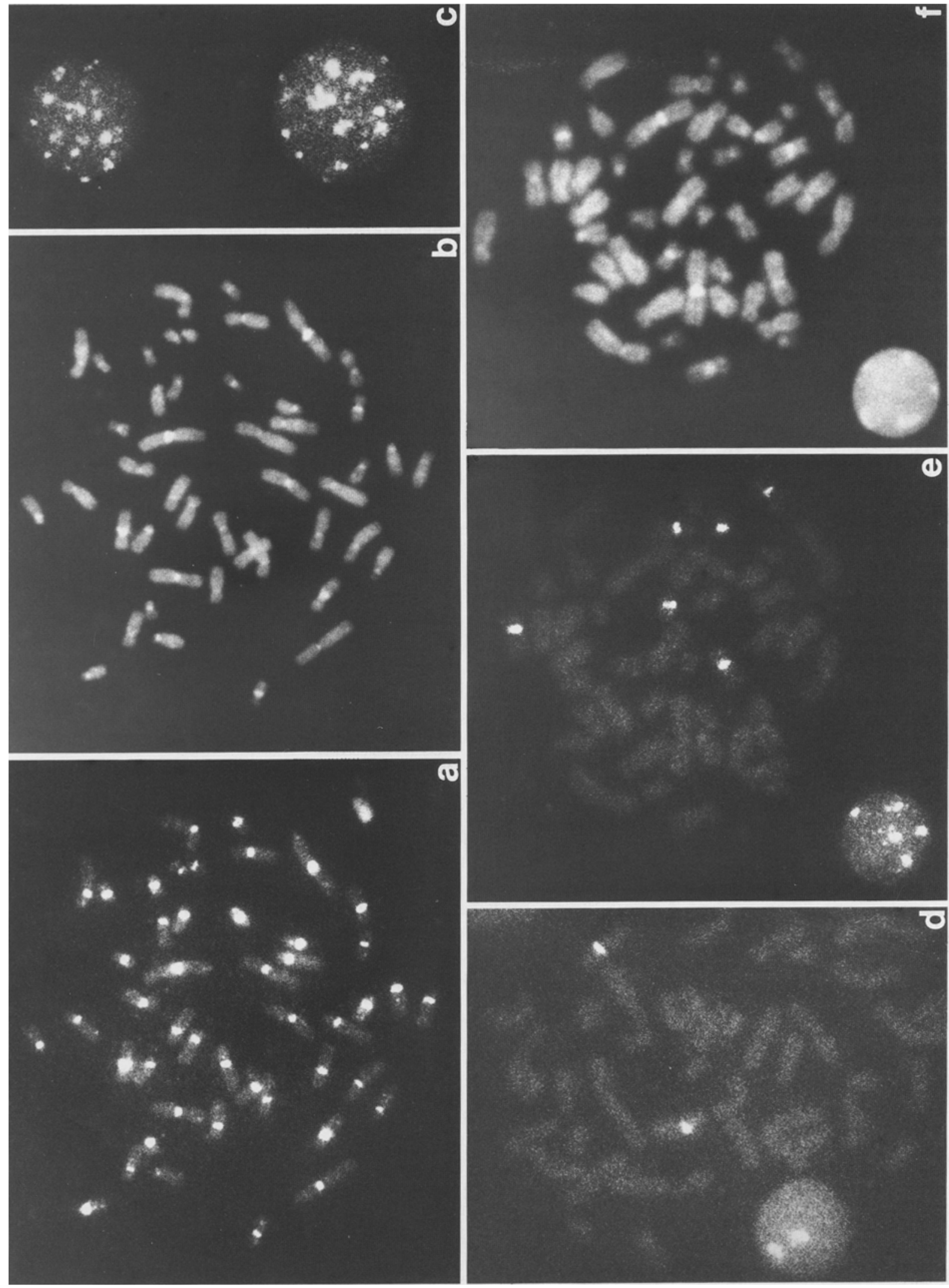

Fig.1a-f. In situ hybridization experiments of PCR-amplified probes generated from human genomic and somatic hybrid cell DNA with oligonucleotide primers $\alpha 27$ and $\alpha 30$. Cells were counterstained with propidium iodide (Fig. $2 \mathrm{c}-\mathrm{e}$ ) and DAPI (see below). a In situ hybridization of a PCR-amplified probe generated from male human genomic DNA. Note FITC-signals on the centromeric regions of all chromosomes in a male human lymphocyte metaphase spread. b The same metaphase spread counterstained with DAPI. c Lymphocyte nuclei from the same experiment show numerous clusters of hybridization signals. d In situ hybridization of a PCR-amplified probe generated from the somatic hybrid $\mathrm{Cl} 21$. Hybridization signals on a normal female lymphocyte metaphase spread and an adjacent interphase nucleus mark the centromeric region of the two $\mathrm{X}$-chromosomes. e Staining of the centromeric regions of chromosomes 7,11 and 20 in a normal female lymphocyte metaphase spread obtained after in situ hybridization of a PCR-amplified probe generated from Rurag 6 hybrid cell DNA. In the adjacent nucleus, five signals can be clearly detected, the sixth signal, although present in this nucleus, is located at another focal plane (not shown). f The same metaphase spread counterstained with DAPI 


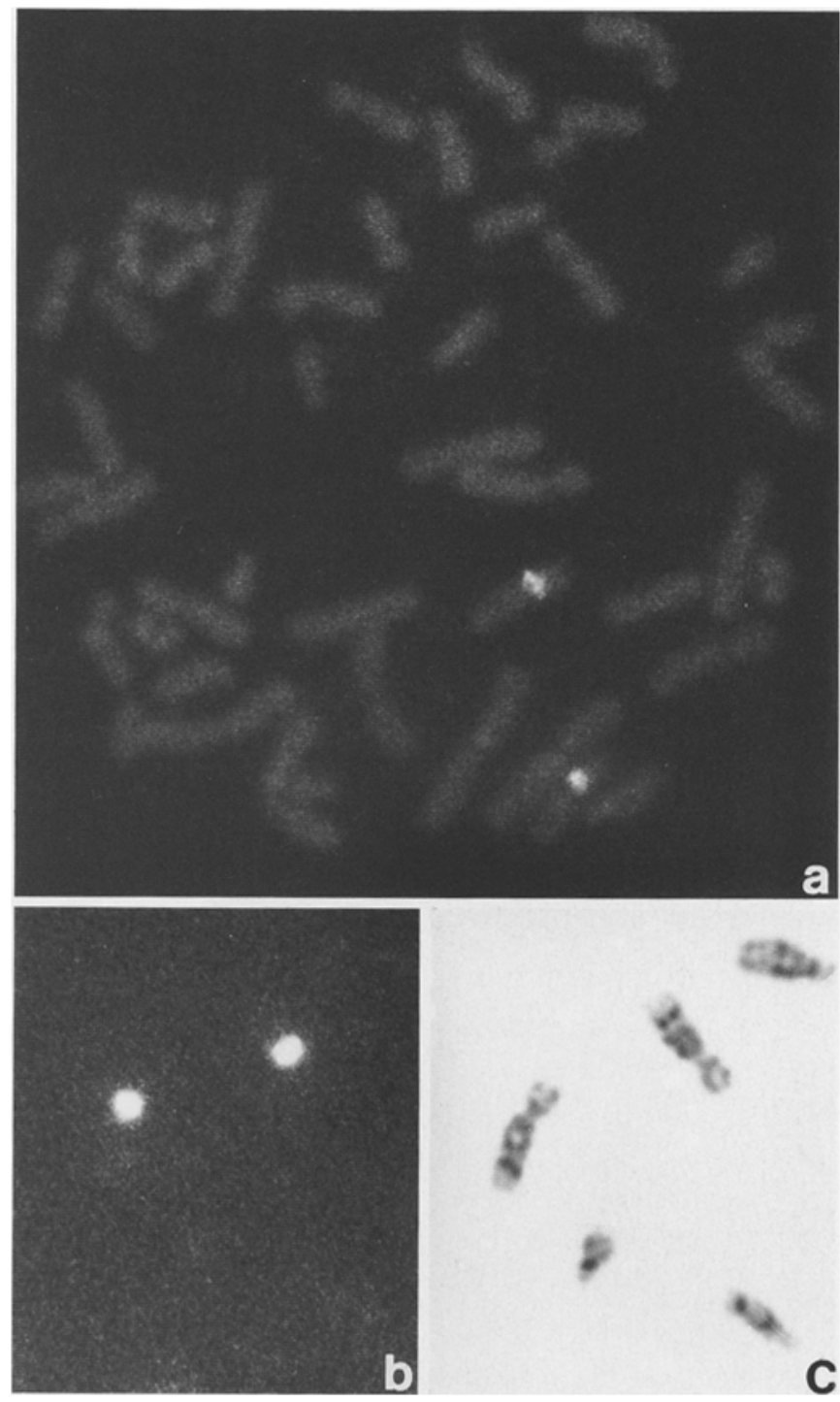

Fig. 2a-c. In situ hybridization of PCR-amplified probes generated from a plasmid DNA library of sorted human chromosomes 8 with primer pair $\alpha 27 / \alpha 30$. Note that FITC-signals are restricted to the centromeric regions of the two chromosomes 8 in a male human lymphocyte metaphase spread (a). Chromosomes were counterstained with propidium iodide. b Two other specifically labeled chromosomes 8 that were GTG-banded before in situ hybridization $(\mathbf{c})$

sorted human X chromosomes (Lengauer et al. 1990). Our present data suggest that the aberrant X-chromosome contained in this line had lost X-specific alphoid sequences.

DNA prepared from plasmid DNA libraries constructed from sorted human chromosomes 1,2 and 8 was also used as a source for PCR with the $\alpha 27 / \alpha 30$ primers. The resulting probes gave strong in situ hybridization signals on the respective chromosomes (see Fig. 2a, b for chromosome 8 ). The specificity of the hybridization signals was dependent on the stringency of the in situ hybridization (see Methods). Under conditions of high stringency, cross-hybridization signals on centromeric regions of other chromosomes were absent or very weak, even in the absence of competitor DNA (see below).
Fluorescence in situ hybridization with alphoid probes generated by PCR with oligonucleotide primers from chromosome-specific alphoid regions

In order to generate chromosome-specific alphoid probes of human genomic DNA by PCR, it is necessary to define oligonucleotide primer pairs that hybridize to chromosome-specific regions of alphoid DNA. Figure 3 shows the results of fluorescent in situ hybridization experiments with probes generated from human genomic DNA with the chromosome-specific primer pairs for human chromosomes $1,6,7,17$ and $X$. Specific signals could be seen on the centromeric regions of the respective chromosomes in normal human lymphocyte metaphase spreads. In the fluorescence microscope, chromosomes could generally be identified by fluorescence banding after DAPI or propidium iodide staining (not shown). In addition, chromosomes were identified using G-banding as described by Gnirke et al. (1991) (see Fig. 3f). Figure 3d (insert) demonstrates the simultaneous localization of the YAC-clone yHPRT at Xq26 (Imai and Olson 1990; Huxley et al. 1991) together with the PCR-generated Xspecific alphoid probe. In some experiments (not shown), cross-hybridization to other centromeres could be seen; however, the specific signal was easily identified from the considerably weaker cross-hybridization signals. This problem was readily alleviated by the addition of either unlabeled total human DNA or alphoid DNA amplified with the primer pair $\alpha 27 / \alpha 30$ as competitor DNA. These PCR-generated chromosome-specific alphoid probes were also useful for interphase cytogenetics (see Fig. 3d, e).

\section{Discussion}

The definition of the centromeric regions of all chromosomes by specific hybridization signals may become of great importance in automated chromosome analysis, e.g., in the automated evaluation of radiation-induced dicentric chromosomes (Meyne et al. 1989). Staining of the centromeric regions from individual chromosomes has made possible the evaluation of numerical chromosome aberrations directly in the interphase nucleus, and has brought about completely new diagnostic possibilities in clinical and tumor cytogenetics (see Introduction for references). In addition, such probes have been exploited in studies of chromosome topography in interphase nuclei, and in nuclei of terminally differentiated cells (Manuelidis and Borden 1988; Emmerich et al. 1989; Popp et al. 1990).

So far, alphoid DNA probes have been generated by cloning procedures that are both time consuming and difficult to perform in all cytogenetic laboratories. PCR provides a rapid and easy alternative for the generation of alphoid DNA probes. In this study, two strategies have been followed. The first strategy makes use of oligonucleotide primers for conserved regions of the alpha satellite monomer (Koch et al. 1989). In this approach, the specificity of PCR-generated alphoid probes varies with the source of the DNA used for amplification. Amplification of human genomic DNA provides probes that hybridize to the centromeric regions of all 

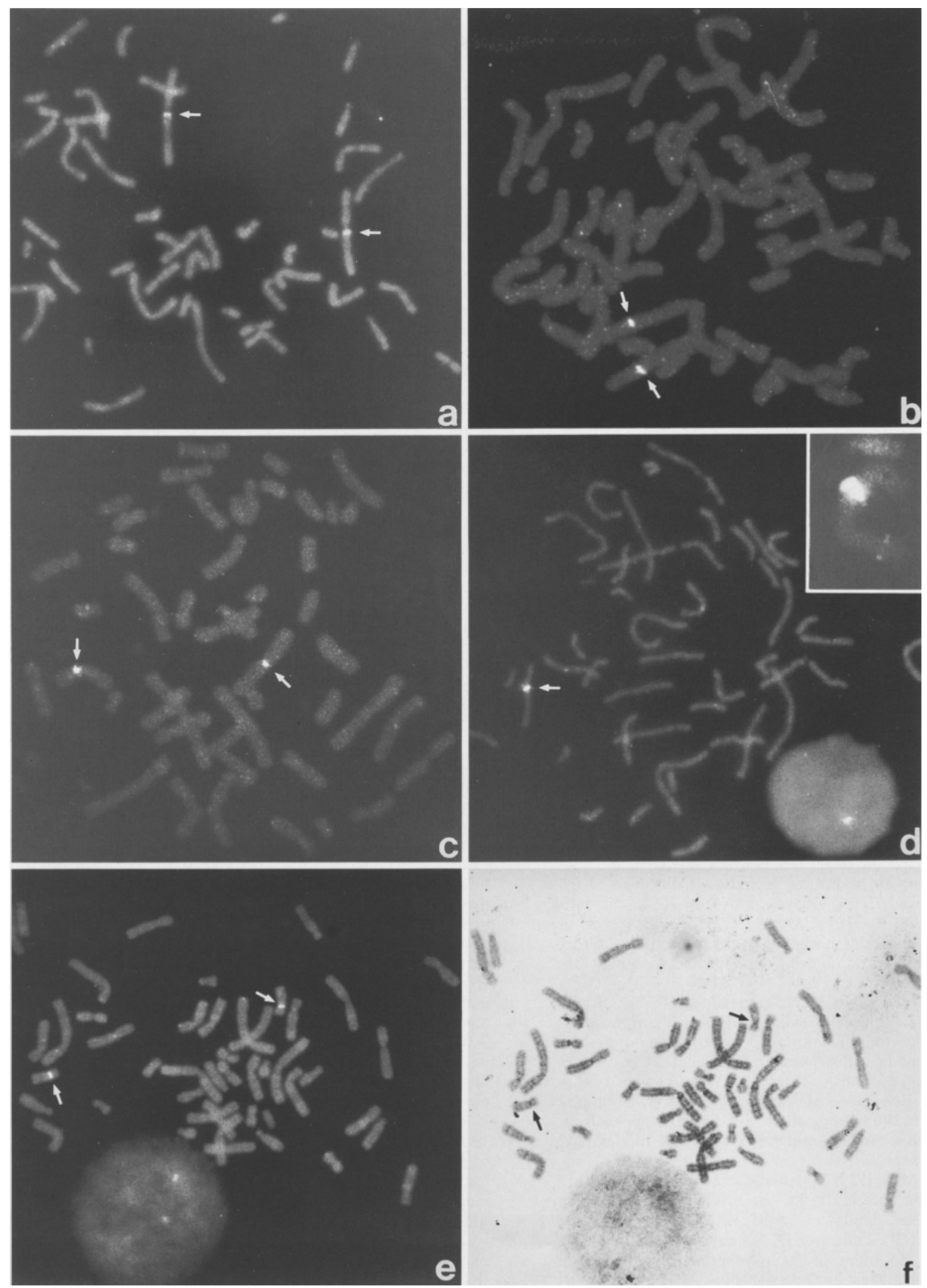

Fig. 3a-f. Complete metaphase spreads from normal PHA-stimulated human lymphocytes after in situ hybridization with PCRamplified biotinylated alphoid DNA probes specific for chromosome 1 (a), chromosome 6 (b), chromosome 7 (c), chromosome X (d) and chromosome 17 (e). Probes were generated from total human genomic DNA with oligonucleotide primers directed to chromosome-specific variable regions of alphoid monomers of the respective chromosomes. Metaphase spreads were counterstained with propidium iodide (a-e) and DAPI (not shown). For chromosome identification, G-banding was performed after in situ hybrid-

ization (f). Arrows indicate specific labeling of the centromeric heterochromatin a of both chromosomes 1 , b of both chromosomes $6, \mathbf{c}$ of both chromosomes $7, \mathbf{d}$ of the $\mathrm{X}$ chromosome in a male cell. Note also a single signal in the accompanying interphase nucleus. Insert. Simultaneous hybridization of the X-centromerespecific probe with YAC-clone yHPRT. The latter clone yields additional signals on both chromatids in Xq26 (banding not shown). e Arrows indicate specific labeling of the centromeric heterochromatin of both chromosomes 17 . f Metaphase spread shown in e after G-banding 
chromosomes, whereas DNA from somatic hybrids with single human chromosomes or DNA libraries from sorted human chromosome types can be used to generate probes for the specific centromere staining of individual chromosomes. The second strategy makes use of oligonucleotide primers from chromosome-specific regions of alphoid monomers. In this case, chromosome-specific alphoid probes can be generated directly from human genomic DNA. A source of ambiguity that limits the usefulness of cloned alphoid DNA probes for the identification of individual chromosomes stems from the fact that some chromosomes share closely related alphoid sequences (Willard and Waye 1987b). In this case, the stringency of in situ hybridization plays a crucial role in the avoidance of cross-hybridization to other chromosomes (Cremer et al. 1986). The construction of oligonucleotide primers for defined small regions of alphoid monomers with high specificity for a given chromosome may provide an improved approach to the generation of chromosome-specific alphoid DNA probes useful for in situ hybridization in clinical and experimental cytogenetics.

Acknowledgements. We would like to thank A. Wiegenstein for photographic work. C. L. was the recipient of a scholarship from the Konrad-Adenauer-Stiftung, and T. C. of a Heisenbergstipendium from the Deutsche Forschungsgemeinschaft. Partial support of this work was provided by DFG grant Cr 59/10-1.

\section{References}

Anastasi J, Le Beau MM, Vardiman JW, Westbrook CA (1990) Detection of numerical chromosomal abnormalities in neoplastic hematopoietic cells by in situ hybridization with a chromosome-specific probe. Am J Pathol 136:131-139

Cremer T, Landegent J, Brückner A, Scholl HP, Schardin M, Hager HD, Devilee P, Pearson P, Ploeg M van der (1986) Detection of chromosome aberrations in the human nucleus by visualization of specific target DNAs with radioactive and nonradioactive in situ hybridization techniques: diagnosis of trisomy 18 with probe L1.84. Hum Genet $74: 346-352$

Cremer T, Lichter P, Borden J, Ward DC (1988a) Detection of chromosome aberrations in metaphase and interphase tumor cells by in situ hybridization using chromosome-specific library probes. Hum Genet 80:235-246

Cremer T, Tesin D, Hopman AHN, Manuelidis L (1988b) Rapid interphase and metaphase assessment of specific chromosomal changes in neuroectodermal tumor cells by in situ hybridization with chemically modified DNA probes. Exp Cell Res 176:199-220

Emmerich P, Loos P, Jauch A, Hopman AHN, Wiegant J, Higgins $M$, White $B N$, Ploeg $M$ van der, Cremer $C$, Cremer $T$ (1989) Double in situ hybridization with digital image analysis. A new approach to study interphase chromosome topography. Exp Cell Res 181:126-140

Green ED, Olson MV (1990) Systematic screening of yeast artificial-chromosome libraries by the use of the polymerase chain reaction. Proc Natl Acad Sci USA 87:1213-1217

Gnirke A, Barnes ST, Patterson D, Schild D, Featherstone T, Olson MV (1991) Cloning and in vivo expression of the human GART gene using yeast artificial chromosomes. EMBO J 10 : 1629-1634

Hopman AHN, Poddighe PJ, Smeets AWGB, Moesker O, Beck JLM, Vooijs GP, Ramaekers FC (1989) Detection of numerical chromosome aberrations in bladder cancer by in situ hybridization. Am J Pathol 135:1105-1117

Huxley C, Hagino Y, Schlessinger D, Olson MV (1991) The human HPRT gene on a yeast artificial chromosome is functional when transferred to mouse cells by cell fusion. Genomics 9:742-750
Imai T, Olson M (1990) Second-generation approach to the construction of yeast artificial chromosome libraries. Genomics 8:297-303

Jabs EW, Persico MG (1987) Characterization of human centromeric regions of specific chromosomes by means of alphoid sequences. Am J Hum Genet 41:374-390

Klever M, Grond-Ginsbach C, Scherthan H, Schroeder-Kurth T (1991) Chromosomal in situ suppression hybridization after Giemsa banding. Hum Genet 86:484-486

Koch JE, Kolvraa S, Petersen KB, Gregersen N, Bolund L (1989) Oligonucleotide-priming methods for the chromosome-specific labelling of alpha satellite DNA in situ. Chromosoma 98:259265

Langer PR, Waldrop AA, Ward DC (1981) Enzymatic synthesis of biotin-labeled polynucleotides: novel nucleic acid affinity probes. Proc Natl Acad Sci USA 78:6633-6637

Lengauer C, Riethman H, Cremer T (1990) Painting of human chromosomes with probes generated from hybrid cell lines by PCR with Alu and L1 primers. Hum Genet 86:1-6

Maniatis T, Fritsch EF, Sambrook J (1982) Molecular cloning: a laboratory manual. Cold Spring Harbor Laboratory, Cold Spring Harbor, NY

Manuelidis L (1978) Chromosomal locations of complex and simple repeated human DNAs. Chromosoma 66:23-32

Manuelidis L, Borden J (1988) Reproducible compartmentalization of individual chromosome domains in human CNS cells revealed by in situ hybridization and three-dimensional reconstruction. Chromosoma 96:397-410

Meyne J, Littlefield G, Moyzis RK (1989) Labeling of human centromeres using an alphoid DNA consensus sequence: application to the scoring of chromosome aberrations. Mutat Res 226:75-79

Mitchell AR, Gosden JR, Miller DA (1985) A cloned sequence, $\mathrm{pH} 82$, of alphoid repeated DNA found at the centromeres of all human chromosomes. Chromosoma 92:369-377

Pinkel D, Gray JW, Trask B, Engh G van den, Fuscoe J, Dekken $\mathrm{H}$ van (1986) Cytogenetic analysis by in situ hybridization with fluorescently labeled nucleic acid probes. Cold Spring Harb Symp Quant Biol 51:151-157

Poddighe PJ, Moesker O, Smeets D, Awwad BH, Ramaekers CS, Hopman AHN (1991) Interphase cytogenetics of hematological cancer: comparison of classical karyotyping and in situ hybridization using a panel of eleven chromosome specific DNA probes. Cancer Res 51:1959-1967

Popp S, Scholl HP, Loos P, Jauch A, Stelzer E, Cremer C, Cremer $T$ (1990) Distribution of chromosome 18 and X centric heterochromatin in the interphase nucleus of cultured human cells. Exp Cell Res 189:1-12

Rosenberg HM, Singer MF, Rosenberg M (1978) Highly reiterated sequences of simiansimiansimiansimiansimian. Science 200:394-402

Waye JS, Willard HF (1985) Chromosome-specific alpha satellite DNA: nucleotide sequence analysis of the 2.0 kilobasepair repeat from the human X chromosome. Nucleic Acids Res 13: 2731-2743

Waye JS, Willard HF (1986) Structure, organization and sequence of alpha satellite DNA from human chromosome 17: evidence for evolution by unequal crossing-over and an ancestral pentamer repeat with the human $\mathrm{X}$ chromosome. Mol Cell Biol $6: 3156-3165$

Waye JS, England SB, Willard HF (1987) Genomic organization of alpha satellite DNA on human chromosme 7: evidence for two distinct alphoid domains. Mol Cell Biol 7:349-356

Willard HF (1985) Chromosome-specific organization of human alpha satellite DNA. Am J Hum Genet 37:524-532

Willard HF, Waye JS (1987a) Hierarchical order in chromosomespecific human alpha satellite DNA. Trends Genet 3:192-198

Willard HF, Waye JS (1987b) Chromosome-specific subsets of human alpha satellite DNA: analysis of sequence divergence within and between chromosomal subsets and evidence for an ancestral pentameric repeat. J Mol Evol 25:207-214 